\title{
Transgenic route runs into sand
}

A spectacular claim that spermatozoa can carry foreign DNA into mouse eggs to make transgenic mice has not been confirmed, but there are no grounds for saying that it should never have been published.

SPECTACUlaR claims make the most cruel disappointments. That is one of the lessons to be learned from the appearance in the current issue of Cell of a report of several parallel failures to repeat what seemed, as recently as June this year, to be a simple way of generating transgenic mice - animals carrying genes from a different species or even genus. Another may be that most genomes are remarkably resistant to accidental pollution by foreign DNA.

The tale is nevertheless interesting in itself, and also important for its bearing on the management of the scientific literature. Earlier this year, an Italian group from Rome reported their success in making transgenic mice by a variation of a standard in vitro fertilization process in which foreign DNA was mixed with the spermatozoa used for fertilizing mouse eggs (Lavitrano, M. et al. Cell 57, 717; 1989). Put simply, the foreign DNA was supposed to be carried into the embryos by the spermatozoa, shown by the same investigation to have a propensity for picking up DNA. Nearly a third of the emergent mice were said to carry the foreign genes, which were said to be transmitted faithfully to a succeeding generation of offspring.

A report such as this was bound to engender both excitement and controversy. The excitement is easily understood. Transgenic mice are invaluable laboratory tools, chiefly as means of inferring how the expression of genes is regulated. There are now several techniques for making them, ranging from the microinjection of DNA into fertilized egg cells to the use of retroviruses carrying segments of foreign DNA together with appropriate controlling elements. But whatever the technique, a transgenic mouse is necessarily a hit-or-miss construction. Among the reasons for the excitement over the Italian report last June is the simplicity of the technique and the success rate reported - nearly a third of the viable artificial embryos emerging seemed to carry foreign DNA.

The reasons why the original report must have aroused controversy are also not far to seek. For one thing, it is surprising that individual spermatozoa can pick up foreign DNA, either as circular plasmids or straight pieces of helical DNA, yet Lavitrano et al. reported that up to 4,000 copies of a plasmid (loaded with an anti- biotic resistance gene for easy detection) may be taken up by a single sperm. Given that, it may have been less surprising that the foreign DNA seems to be integrated in the mouse genome, but last June's speculation that the mechanism might have been responsible, in the course of evolution, for the transfer of genetic material between species was bound to send shivers down many a spine. In a comment accompanying last June's publication in Cell, Max L. Birnstiel and Meinrad Busslinger understandably compared the report with the earlier reports of what is now known as 'cold fusion'.

That is the excitement and the controversy. The disappointment is the letter from four well-known mouse-genome manipulators (Ralph L. Brinster, Eric P. Sandgren and Richard R. Behringer, all from the University of Pennsylvania, together with Richard D. Palmiter from the University of Washington at Seattle) in the latest issue of Cell. They say that they have failed to confirm the integration of foreign DNA into artificially fertilized mice in eight series of experiments, two of which followed essentially the same experimental protocol as the Italian. For good measure, they also report that seven other laboratories, spread from Budapest to Pasadena, have similarly negative results.

So what can have gone wrong? One possible answer is simply, "Nothing". Cell also publishes in its most recent issue a letter from Lavitrano et al. that is a model of how people whose results are not confirmed should respond to challenge: "the inability to reproduce our results ... suggests ... a serious problem of which we were not aware", "when we received news of negative results . . ., we re-examined the procedure ... no obvious point has so far emerged", and so on. By the account of Brinster et al., the authors have also readily responded to requests for reagents and other materials that would allow exact replication of their protocols. Lavitrano et al. volunteer that, while continuing to study their transgenic mice, they are also planning that their work should be repeated at another laboratory. It may yet emerge that the original report was correct, but valid only in the particular circumstances of the Rome experiment. It seems unlikely that the phenomenon described will be more generally valid.

Meanwhile, attention will concentrate on one still-puzzling feature of the original report. The plasmid DNA apparently easily incorporated into mouse spermatozoa and thus into mouse genomes was distinguished by two sites at which it could be cut by a particular restriction (cutting) enzyme, but the foreign DNA incorporated into intact mice seemed to have lost one of these sites. Everybody concerned has followed the original suggestion that there must be some process at work that rearranges the DNA before it is incorporated, but that is almost as puzzling a circumstance as the possibility that spermatozoa can pick up thousands of copies of plasmid DNA from the medium that surrounds them.

So there remains the question provoked by Brinster et al., who round off their report of their failure to replicate the original results with some homilies on the proprieties of the publication process. They make four points, three of which are platitudinous: exciting research reports do not always emerge from distinguished laboratories; the more "important" are claims, the more quickly will they be tested; and verifications (or the opposite) should first be reported in science journals, even if they are afterwards put out in press releases. Almost everybody will agree.

The fourth point is the puzzle. Brinster et al. say that "the central aspect of the process of verification is the objective and methodological resolution of a question

best accomplished in a cooperative manner ... as is occuring ... in this case." They add that, whatever the outcome of the investigations now planned, "those in research, and others . .." will have learned a lot about "how scientific knowledge evolves" (sic).

Will they? Brinster et al. would have done better to acknowledge that there is a further question to be asked: is the peerreview system the universal safeguard against error it is supposed to be? In an ideal world, referees can keep on asking questions of authors who report extraordinary results until all possible doubts are exorcised, but that is not the real world in which we live. Implicit in what Brinster et al. say is their assumption that people with remarkable results to report have a right to see them published quickly. But may it not be that it is the extraordinary results that need most checking time?

John Maddox 